\title{
Aula expositiva e Paulo Freire
}

\author{
Mauro Antonio Andreata ${ }^{1}$
}

\section{RESUMO}

Nas tradicionais aulas expositivas, os alunos ficam em silêncio e imóveis. Mesmo quando o professor é um excelente expositor, os resultados da verificação da aprendizagem costumam ser inexpressivos. Preocupados com o mau desempenho nas verificações da aprendizagem e com a passividade dos alunos, alguns autores fizeram críticas à aula expositiva. Os professores brasileiros, todavia, costumam conhecer apenas a técnica expositiva. Por isso, discutimos as principais vantagens e desvantagens da aula expositiva, apresentamos as características de uma boa aula expositiva e, com base nos princípios educacionais freirianos, fazemos dez sugestões para que as potencialidades da aula expositiva sejam aproveitadas ao máximo. Em especial, destacamos a importância de incluir o diálogo entre professor e educandos e entre os educandos nas aulas. Nossa proposta é aplicável em qualquer sala de aula, tanto urbana quanto rural, sem a necessidade de dispor de recursos sofisticados.

PALAVRAS-CHAVE: Paulo Freire. Aula expositiva. Diálogo.

\section{Expositive class and Paulo Freire}

\begin{abstract}
In traditional expositive classes, students are silent and immobile. Even when the teacher is an excellent speaker, the results of the learning evaluation are usually unimpressive. Concerned with the poor performance in the verifications of the learning and the passivity of the students, some authors criticized the expositive class. Brazilian teachers, however, usually know only the expositive technique. For this reason, we discuss the main advantages and disadvantages of the expositive class,
\end{abstract}

\footnotetext{
${ }^{1}$ Doutor em Física. Professor associado na Universidade Federal de Goiás - Regional Catalão, Unidade Acadêmica Especial de Física. https://orcid.org/0000-0002-4995-5786. andreatamauro@gmail.com.
} 
we present the characteristics of a good expositive class and, based on the Freirian educational principles, we make ten suggestions so that the potential of the expositive class is maximized. In particular, we emphasize the importance of including the dialogue between teacher and students and between the students in the classes. Our proposal is applicable in any classroom, both urban and rural, without the need for sophisticated resources.

KEYWORDS: Paulo Freire. Expositive class. Dialogue.

$$
* * *
$$

Não gosto das explicações em forma de discurso. Os jovens prestam pouca atenção nelas e não as retêm. As coisas! As coisas! Nunca terei repetido suficientemente que damos poder demais às palavras. Com nossa educação tagarela, só criamos tagarelas. (ROUSSEAU, 2004, p. 236)

Como já o disse alhures, uma lição deve ser uma resposta. Se ela for uma resposta, será escola ativa, mesmo que os alunos fiquem apenas a escutar.

(CLAPARÈDE, 1958c, p. 142)

\section{Introdução}

Alguns autores fazem críticas à técnica ${ }^{2}$ expositiva ou acroamática ${ }^{3}$. A sua eficiência é fortemente questionada: "Estudos após estudos indicam que o método expositivo é muito ineficaz: a transmissão é eficiente, mas a recepção é quase desprezível” (HEUVELEN, 1991, p. 895, tradução nossa ${ }^{4}$ ).

Outra crítica diz respeito ao psitacismo ${ }^{5}$ :

\footnotetext{
${ }^{2}$ Os livros de didática costumam distinguir método, técnica e procedimento. Por exemplo: "Método - O significado etimológico da palavra método é: caminho a seguir para alcançar um fim. Para nosso objetivo podemos conceituar método como sendo um roteiro geral para a atividade. O método indica as grandes linhas de ação, sem se deter em operacionalizá-las. Podemos dizer que o método é um caminho que leva até certo ponto, sem ser o veículo de chegada, que é a técnica. Técnica - É a operacionalização do método. Procedimentos - Maneira de efetuar alguma coisa. Consiste em descrever as atividades desenvolvidas pelo professor e as atividades desenvolvidas pelos alunos" (PILETTI, 1987, p. 102-103, grifo do autor). Alguns autores, contudo, usam as palavras método, técnica e procedimento como sinônimos intercambiáveis. Respeitamos essa intercambiabilidade em nosso texto.

${ }^{3}$ Acroamático: oral; diz-se do método de ensino do filósofo grego Aristóteles (384-322 a.C.) em que os discípulos apenas ouviam sem fazer qualquer interrupção; que agrada ao ouvido; que é sublime, elevado.

${ }^{4}$ Texto original (em inglês): "Study after study indicates that this expository method is very ineffective - the transmission is efficient but the reception is almost negligible" (HEUVELEN, 1991, p. 895).

${ }^{5}$ Psitacismo (do latim psittacus = papagaio): verborreia, verbosidade, logorreia, loquacidade, eloquência abundante e estéril; decoreba.
} 
Acusamos de verbalismo a Escola Tradicional, onde, no entanto, é sobretudo o professor quem fala, uma vez que os alunos só o devem fazer quando interrogados. Os seus estados normais são, por isso, a imobilidade e o silêncio (BARTOLOMEIS, 1984, p. 15).

Ao condenar a costumeira verborreia dos professores, eis como se expressou o educador cearense Lauro de Oliveira Lima (1921-2013): "Nosso professor é como o cão de Pavlov ${ }^{6}$ : quando toca a campainha começa a salivar" (LIMA, 1979, p. 23). Os antigos livros de ensino já mencionam essas desvantagens: "Por método de exposição significamos aqui uma apresentação oral sem discussão ou participação apreciável dos alunos. Os estudantes ouvem e tomam notas - ou fazem outra coisa, conforme ditarem suas naturezas" (THORNDIKE; GATES, 1936, p. 293-294). Os modernos livros de ensino também indicam as desvantagens da técnica expositiva:

Nessa visão de ensino, a aula é o espaço em que o professor fala, diz, explica o conteúdo, cabendo ao aluno anotá-lo para depois memorizá-lo. Daí poder prescindir da presença do próprio aluno, pois, se há um colega que copia tudo, basta fotocopiar suas anotações e estudá-las, para dar conta dessa maneira de memorizar os conteúdos (ANASTASIOU, 2009, p. 17).

Talvez com algum exagero, certos autores consideram que só o professor se beneficia na aula expositiva:

O método tradicional de ensino é de eficiência extraordinária para desenvolver o professor, porque ele é quem executa os atos que conduzem aos objetivos formativos, enquanto os alunos são submetidos a aulas de exposição que não lhes dão oportunidade de desenvolvimento. Por isso um colega nosso, de índole irônica, costumava dizer que, numa aula, só quem aprende é o professor

\footnotetext{
${ }^{6}$ Ivan Petrovich Pavlov (1849-1936), fisiólogo russo. Prêmio Nobel de fisiologia ou medicina de 1904.
} 
(FROTA-PESSOA; GEVERTZ; DA SILVA, 1970, p. 45, grifo do autor).

A técnica expositiva seria tão ruim que nem mesmo efeitos nocivos ela consegue produzir com eficiência:

Por sorte, o método tradicional de ensino é pouco eficiente até mesmo em seus aspectos nocivos, de modo que muitos estudantes conseguem atravessar a escola preservando suas qualidades básicas, apesar de sua influência perniciosa. Mas não nos enganemos. Para consegui-lo, muitas vezes o adolescente tem de desenvolver mecanismos de defesa pouco recomendáveis (FROTAPESSOA; GEVERTZ; DA SILVA, 1970, p. 57).

Os professores brasileiros, todavia, costumam conhecer apenas a técnica expositiva. Outros autores já constataram isso: "Um problema generalizado é que os professores possuem um número muito reduzido de técnicas em seu repertório didático" (BORDENAVE; PEREIRA, 2008, p. 122). Paulo Reglus Neves Freire (1921-1997) estabelece que, em todos os níveis do ensino brasileiro, "há uma quase enfermidade da narração. A tônica da Educação é preponderantemente esta - narrar, sempre narrar" (FREIRE, 2010, p. 65). O professor pernambucano indica-nos também o mal resultante: "A narração, de que o educador é o sujeito, conduz os educandos à memorização mecânica do conteúdo narrado" (FREIRE, 2010, p. 66).

Talvez o problema não seja exatamente com a técnica expositiva, mas com seu uso excessivo por maus professores:

[...] não há algo intrinsecamente errado com a aula expositiva como mecanismo de ensino. Sua imagem está tão desgastada simplesmente em razão do uso ou mau uso que dela se faz. Isto é, muitas vezes a aula expositiva é o único recurso instrucional utilizado tornando-se, portanto, rotineiro e sofrendo um desgaste 
natural. Em outros casos, ela é usada em situações inoportunas ou é mal dada, prejudicando decisivamente sua imagem e conduzindo a resultados medíocres em termos de aprendizagem. Infelizmente, na maioria das vezes, ocorre ainda uma indesejável combinação entre essas duas possibilidades o que leva ao uso excessivo de aulas expositivas mal ministradas (MOREIRA7 7 , 1985, p. 63).

Sim, ensinar usando uma só técnica produz monotonia nas aulas e desinteresse nos discentes. Talvez seja difícil, entretanto, eliminar a aula expositiva do ensino: "A expressão verbal será sempre preeminente na escola como o é na vida, devido a sua enorme vantagem quanto ao tempo, espaço, material e técnica" (THORNDIKE; GATES, 1936, p. 144). Além disso, dependendo do preparo do professor, as palavras podem despertar e conscientizar os educandos, como observa ${ }^{8}$ o filósofo francês Georges Gusdorf (1912-2000):

A palavra do Mestre é uma palavra mágica. Ao apelo de um espírito, outro espírito desperta; pela graça de um encontro, uma vida foi mudada. Não que essa vida passe daí em diante a imitar a cimeira existência que, num dado momento, cruzou e iluminou a sua. Não que essa vida se tenha mudado à semelhança da outra que a visitou; foi-o à sua semelhança, própria e singular. Jazia na ignorância e passou a conhecer-se e pertencer-se, a depender unicamente de si própria, a sentir-se responsável pela realização que doravante cumprirá (GUSDORF, 1970, p. 19).

\footnotetext{
${ }^{7}$ Curiosamente, o mesmo autor, alguns anos depois, enuncia o Princípio da não utilização do quadro de giz. Eis a justificativa apresentada: "Assim como o livro de texto simboliza a autoridade de onde 'emana' o conhecimento, o quadro de giz simboliza o ensino transmissivo, no qual outra autoridade, o professor, parafraseia, ou simplesmente repete, o que está no livro, ou resolve exercícios, para que os alunos copiem, 'estudem' na véspera da prova e nela repitam o que conseguem lembrar. É difícil imaginar ensino mais antiaprendizagem significativa, e muito menos crítica, do que esse: o professor escreve no quadro, os alunos copiam, decoram e reproduzem. É a apologia da aprendizagem mecânica, mas, ainda assim, predomina na escola" (MOREIRA, 2015, p. 239).

${ }^{8}$ Observação feita após recordar a célebre lição de geometria dada por Sócrates a um escravo, na qual, perante algumas figuras traçadas na areia e metodicamente interrogado, o escravo define certas verdades muito próximas do teorema de Pitágoras (GUSDORF, 1970, p. 19).
} 
Justamente por causa dessa possibilidade, propomos que os princípios educacionais freirianos ${ }^{9}$ sejam introduzidos na aula expositiva, em especial o diálogo com os alunos. Não um diálogo vertical, imposto, mas diálogo horizontal, respeitando os saberes dos educandos e buscando, junto com os alunos, a superação desses saberes. Isso porque "o educador e a educadora progressistas necessitam estar cientes de que não sabem tudo e o educando tem o direito de saber que não ignora tudo, que necessita saber melhor o que já sabe e conhecer o que ainda não conhece” (ZANETTI, 2010, p. 195).

Por que, entre tantos autores, escolhemos o Paulo Freire? Nós o escolhemos em virtude da flexibilidade e da atualidade dos seus princípios educacionais. As ideias do Paulo Freire têm inspirado educadores não só no Brasil e na América Latina, mas no mundo todo. Por exemplo, Jack Mezirow (1923-2014), sociólogo estadunidense, desenvolveu o conceito de aprendizagem transformadora inspirado por Paulo Freire, entre outros autores (MEZIROW, 2013). Asoke Bhattacarya (1950- ), professor indiano, escreveu um livro sobre a vida e a obra do Paulo Freire intitulado Paulo Freire: Rousseau of the twentieth century10 (BHATTACARYA, 2011).

\section{A aula expositiva}

Quando surgiu a técnica expositiva?

O método expositivo é um processo de comunicação oral anterior à descoberta da escrita e da imprensa. Pode-se imaginar, por exemplo, o professor das universidades medievais dispondo deste único recurso para fazer seus alunos aprenderem. A inexistência de livros levava-o a repetir (recitações-leitura) o texto tantas vezes quantas necessárias para que os alunos o decorassem (hipótese em

\footnotetext{
9 "É iano, com $\boldsymbol{i}$, o sufixo que se deve usar para indicar o adjetivo referente a um nome próprio. Assim: shakespeariano (e não 'shakespeareano'), euclidiano (e não 'euclideano'), rodriguiano, rosiano (de Guimarães Rosa), machadiano, faulkneriano, etc. A instrução se aplica também a adjetivos referentes a nomes geográficos: cabo-verdiano, alasquiano, açoriano, cingapuriano, iraquiano. Exceções: acreano, taubateano e coreano" (MARTINS FILHO, 1997, p. 141, grifo do autor).

${ }^{10}$ Paulo Freire: Rousseau do século vinte (tradução nossa).
} 
que se poderia supor que os alunos podiam ser até analfabetos) (LIMA, 1973, p. 444).

O ensino oral é bem antigo. O filósofo grego Platão (427-347 a.C.), o primeiro pedagogo da história, costumava usá-lo:

O ensino de Platão era, sobretudo, oral. O ensino oral, mais vivo, capaz de revelar até pela entonação da voz os mais finos matizes de um pensamento, as suas oscilações, dúvidas e alternativas, sempre foi o preferido de Platão. Os discípulos, porém, tomavam notas dos cursos (COSTA, 1949, p. 46).

Antes de Platão, seu mestre, Sócrates (469/470-399 a.C.), já o usava: "Ele próprio não escreveu nada. É um filósofo sem obra escrita. Sócrates era um homem de discussão, de diálogo" (GAUTHIER; TARDIF, 2013, p. 36). Antes de Sócrates, o ensino oral já era usado pelos sofistas, considerados os "iluministas gregos", os primeiros professores, os quais eram professores ambulantes, pois iam de cidade em cidade e, além disso, recebiam compensação pecuniária por suas aulas. Eles se serviam com invulgar eficiência da discussão:

Para Sócrates e também para os sofistas, a discussão com o outro não é apenas um meio educativo, mas o recurso pelo qual se produz a própria educação e, ao mesmo tempo, a finalidade da formação, que é possível reconhecer pela aquisição de uma "competência discursiva". Ser instruído é, para os sofistas, "saber falar", "saber argumentar" em público segundo as regras pragmáticas da retórica. Para Sócrates, é ser capaz de desenvolver uma argumentação lógica para legitimar as assertivas (GAUTHIER; TARDIF, 2013, p. 38).

Existe, contudo, um grande risco. Desde a Antiga Grécia ele tem marcado presença: 
Os métodos empregados [pelos sofistas], a "discussão", que Roma e a Idade Média reatarão, a repetição de memória de discursos preparados, a aquisição de um saber tão superficial quanto pretensioso, a argumentação formal e artificial, logo fizeram essa educação cair num formalismo perigoso. As palavras, o verbalismo, a declinação harmoniosa ou hábil dos pensamentos, levaram a melhor sobre as próprias ideias, a sinceridade e a verdade. A arte de sustentar o pró e o contra, o malabarismo verbal e a habilidade em fazer triunfar até as piores causas, marcaram durante séculos a cultura superior (GAL, 1989, p. 32).

Eis algumas definições ${ }^{11}$ possíveis da aula expositiva, ou método expositivo ou técnica expositiva:

A exposição didática - também chamada palestra de explanação é o procedimento pelo qual o professor, valendo-se de todos os recursos da boa linguagem didática, apresenta aos alunos um novo tema, definindo-o, analisando-o e explicando-o (MATTOS, 1959, p. 206).

Esta técnica [a técnica expositiva] tem ampla aplicação no ensino de todas as disciplinas e em todos os níveis. Consiste na exposição oral, por parte do professor, do assunto da aula. É a técnica mais usada em nossas escolas [no Brasil] (NÉRICI, 1968, p. 258).

A técnica mais tradicional de ensino é a técnica expositiva ou aula expositiva, que consiste na apresentação de um tema logicamente estruturado. Essa técnica é das mais antigas no campo do ensino, assim como a cópia, o ditado e a leitura (PILETTI, 1987, p. 106).

\footnotetext{
${ }^{11}$ Devemos ter cuidado para não considerar cada definição como indicação precisa de uma prática real, afinal "nossas denominações correspondem a aspectos particulares, a maneiras de fazer predominantes, ao caráter geral de um sistema. Mas são realmente, em boa parte, abstrações cômodas, que apenas permitem ver com clareza e saber o que se faz, o caminho em que nos metemos" (LEIF; RUSTIN, 1960, p. 228).
} 
Por que a aula expositiva é tão sedutora? Quem não gosta de assistir uma boa aula expositiva? Alguns autores responsabilizam o filósofo, psicólogo e pedagogista12 alemão Johann Friedrich Herbart (1776-1841):

Herbart elaborou uma metodologia sedutora e fácil, um plano sistemático de lição que teve enorme sucesso na medida em que pode aplicar-se a qualquer disciplina e a qualquer intenção, e na medida em que fornece ao professor a segurança de um caminho bem traçado, sem obstáculos e sem surpresas (CLAUSSE, 1976, p. $92)$.

Se Herbart se fez ouvir... é porque tem um sistema rico de fórmulas: e sabemos qual o império, a fascinação que exerce sobre os espíritos o despotismo de uma doutrina sistemática. A preguiça humana repousa de bom grado no leito macio de uma doutrina acabada, que previu até as últimas minúcias (COMPAYRÉ apud CLAPARÈDE, 1958a, p. 12).

Tais princípios [herbartianos], que priorizavam a apreensão de conteúdos científicos, literários e filosóficos na formação dos educandos, acabaram forjando um dos mais poderosos métodos de ensino: "os cinco passos formais", facilmente transformados no "modo natural de ministrar aulas" - o "método expositivo". Os "cinco passos" - preparação, apresentação, associação, generalização e aplicação - indicavam um modo razoavelmente simples e fácil de conduzir o processo de aprendizagem, e esta foi uma das condições técnicas essenciais para o seu sucesso e disseminação entre os professores (GHIRALDELLI Jr., 1994, p. 22).

Quando os passos formais chegaram ao Brasil? Na virada do século XIX para o século XX, através das obras de Francis Parker ${ }^{13}$, segundo

12 Pedagogista: Pessoa versada em pedagogia; teórico da educação; indivíduo que pesquisa ou divulga temas relacionados à pedagogia. 
Ghiraldelli Jr. (1994). Nesse mesmo período, na Europa, surgia a Escola Nova, a qual questionou a Escola Tradicional e, em especial, o método herbartiano.

Como seria uma boa aula expositiva? Uma boa aula expositiva seguiria, na visão da Escola Tradicional, o método de Herbart. O método de Herbart é formalizado em cinco passos ${ }^{14}$ :

1. Preparação. Cria-se o ambiente - tanto externo como interno para o desenvolvimento de ideias. Ideias antigas são trazidas do subconsciente e cultiva-se a atenção.

2. Apresentação. As lições são apresentadas aos alunos com o uso de ilustrações, de modo a torná-las tão concretas quanto possível.

3. Associação. São enfatizadas tanto as semelhanças quanto as diferenças entre as ideias antigas e novas. Isso desenvolve a ordem e a consistência de pensamento.

4. Generalização. Este é um método de simplificação qualitativa, de modo que um número cada vez maior de fatos possa ser compreendido em seu significado mais amplo.

5. Aplicação. O conhecimento tem de ser utilizado e tornado parte de nossa vida cotidiana (MAYER, 1976, p. 353, grifo do autor).

Os passos formais da instrução deviam ser um auxílio temporário para o professor iniciante no preparo de uma lição oral para toda uma classe, entretanto:

O homem natural gosta de uma fórmula que lhe poupe o trabalho de pensar, e a fórmula conhecida como os cinco passos formais de instrução foi adotada com tanto ardor nos colégios de treinamento

\footnotetext{
${ }^{13}$ Francis Wayland Parker (1837-1902), professor estadunidense. De 1872 a 1875, esteve na Alemanha estudando os novos métodos de ensino. Em especial, o método de Herbart. O livro de Francis Parker Talks on teaching (1883) foi traduzido em português, em 1909, como Palestras sobre ensino.

14 "Herbart dividiu o processo de ensino em quatro partes, por ele chamadas clareza, associação, sistema e método. Tuiskon Ziller (1817-1882), filósofo e pedagogo alemão, dividiu a primeira dessas partes em outras duas e Wilhelm Rein (1847-1929), pedagogo alemão, substituiu as denominações propostas por Herbart e Ziller por outras, mais claras e mais simples: preparação, apresentação, associação (ou comparação), recapitulação (ou generalização) $e$ aplicação" (AGUAYO, 1970, p. 63, grifo do autor).
} 
que nenhum estudante podia arriscar-se a afastar-se dela. Lições de todos os tipos eram forçadas no mesmo molde, às vezes de modo arbitrário (RAYMONT, 1961, p. 161, grifo do autor).

A partir do estabelecimento dos passos formais da instrução, temos o seguinte cenário:

Ensinar significava dar uma lição, e dar uma lição significava postar-se diante da classe, equipado com quadro-negro, giz e apagador, com ilustrações preparadas, com mapas e aparelhos, e por esses meios demonstrar e lecionar, ou alternativamente, quando o assunto era suscetível, manter um fogo rápido de pergunta e resposta. Essa foi a espécie de esforço aprendido durante o estágio aluno-mestre, e aperfeiçoado no colégio de treinamento, de $1850 \mathrm{em}$ diante [na Inglaterra]. O método do giz e conversa havia substituído o método do livro e açoite. Deve ser acrescentado, no entanto, que embora os livros, com raras exceções, fossem bem escassos nas escolas elementares, o açoite continuou muito em evidência (RAYMONT, 1961, p. 157).

Quais são as principais vantagens e desvantagens da aula expositiva? Um antigo livro apresenta as vantagens e desvantagens da técnica expositiva:

Vantagens da exposição didática:

a) é altamente condensadora:

- reduzindo o assunto aos seus dados essenciais;

- parcelando a matéria em doses assimiláveis pelos alunos;

- reinterpretando a matéria em termos simples, claros e acessíveis aos alunos;

b) é, por excelência, econômica, permitindo a cobertura de um máximo de matéria com um mínimo de tempo e de trabalho; 
c) é útil na fase introdutória da aprendizagem para definir, fundamentar e organizar o campo de estudo dos alunos;

d) é disciplinadora do raciocínio e da linguagem dos alunos; quando bem conduzida.

Limitações da exposição didática:

a) depende do interesse e da atenção dos alunos, o que torna sua eficácia bastante problemática;

b) cria nos alunos uma atitude de passiva receptividade, pouco favorável à autêntica aprendizagem, que deve ser sempre dinâmica e ativa;

c) torna-se cansativa e por demais pesada quando empregada em forma maciça e exclusiva, sem material intuitivo para reforçá-la e torná-la mais concreta e compreensível;

d) sua eficácia se limita à fase inicial da aprendizagem, não fazendo a cobertura de todo o processo da aprendizagem; assegura, apenas, a compreensão inicial do assunto em tela; é tão somente um procedimento introdutório (MATTOS, 1959, p. 208-209).

Um livro recente apresenta as vantagens e desvantagens da técnica expositiva: Segundo Vasconcellos (2014), a metodologia expositiva não leva em conta uma série de importantes fatores revelados pelas ciências pedagógicas contemporâneas. Não leva em conta que: o aluno é um ser concreto (e não o ideal dos manuais pedagógicos); há necessidade de motivação para a aprendizagem (esta não pode ser ignorada ou suposta); o conhecimento se dá na relação sujeito-objeto-realidade, com a mediação do professor (e não pela simples transmissão); o conhecimento se dá pela ação do educando sobre o objeto de estudo (e não pela ação do professor); existem diferentes estágios de desenvolvimento (o aluno não é um adulto em miniatura); o aluno traz uma bagagem cultural (o novo conhecimento não se dá a não ser a partir do anterior); o trabalho em sala de aula tem uma dimensão coletiva (não é uma justaposição de individualidades). Em resumo: 
Basicamente, então, poderíamos dizer que o grande problema da metodologia expositiva, do ponto de vista pedagógico, é seu alto risco de não aprendizagem, em função do baixo nível de interação sujeito-objeto de conhecimento-realidade (o grau de probabilidade de interação significativa é muito baixo) (VASCONCELLOS, 2014, p. 26, grifo do autor).

Para Vasconcellos (2014), a metodologia expositiva ainda perdura em função dos seguintes fatores: legitimação social; legitimação por avaliação; legitimação pela tarefa a cumprir; didática do "atalho"; baixo custo; comodidade para o professor; reprodução social.

Eis as consequências, na opinião do Vasconcellos (2014), do uso da metodologia expositiva: o aluno não aprende; o professor não ensina; o aluno pobre é expulso da escola; o aluno que fica é educado para a submissão; há um embrutecimento; o professor é levado à doença.

\section{A aula expositiva com enfoque freiriano}

Reconhecemos e defendemos a necessidade de usar métodos ativos no ensino-aprendizagem (ANDREATA; BARROS, 2017a). Não podemos ficar inertes enquanto a tradicional aula expositiva impera em nosso país. Não estamos propondo uma revolução, mas uma mudança suave e provisória, um primeiro passo até atingirmos as transformações necessárias na educação brasileira. A ideia é não intimidar os professores (muitos são rotineiros), afinal existem muitas propostas em vários livros e revistas, mas não são adotadas na prática cotidiana dos professores. Por que será? Medo de mudar? Temem mudanças bruscas?

Existem professores que não querem variar sua forma de ensinar; outros querem, mas não sabem como, outros querem e sabem mas não sabem aplicar e ainda outros que querem e sabem, mas não 
podem fazê-lo por motivos alheios à sua vontade (BORDENAVE; PEREIRA, 2008, p. 122).

Às vezes, existe um bloqueio psicológico:

Embora uma mudança de métodos de ensino possa parecer algo simples, para muitos professores ela implica um esforço psicológico fora do comum. Em parte, devido a sua escassa preparação pedagógica, a adoção de métodos ativos, por exemplo, impressiona ao professor tradicional como algo complexo e cheio de riscos (BORDENAVE; PEREIRA, 2008, p. 304).

Em sua obra Pedagogia da autonomia, Paulo Freire (2007) enumera os saberes necessários à prática educativa, os quais são classificados pelo próprio autor em três grupos: 1) Não há docência sem discência; 2) ensinar não é transferir conhecimento; 3) ensinar é uma especificidade humana. Cada um desses grupos engloba os princípios que o autor considera como indispensáveis à boa prática docente. Os saberes supracitados sintetizam os princípios educacionais freirianos, sua maneira de pensar e fazer educação, visando produzir uma existência humana digna, justa e solidária.

Com base nos princípios educacionais freirianos, apresentamos a seguir sugestões para que as potencialidades da aula expositiva sejam aproveitadas ao máximo. Esperamos que o leitor considere nossa proposta como uma possibilidade entre muitas outras, que se sinta desafiado por nosso texto e não abandone sua postura crítica15. Queremos deixar bem claro que não estamos fornecendo receitas para ensinar bem, afinal o método

\footnotetext{
15 "Estudar seriamente um texto é estudar o estudo de quem, estudando, o escreveu. É perceber o condicionamento histórico-sociológico do conhecimento. É buscar as relações entre o conteúdo em estudo e outras dimensões afins do conhecimento. Estudar é uma forma de reivindicar, de recriar, de reescrever - tarefa de sujeito e não de objeto. Desta maneira, não é possível a quem estuda, numa tal perspectiva, alienar-se do texto, renunciando assim à sua atitude crítica em face dele" (FREIRE apud GADOTTI, 2004, p. 29, grifo do autor). Recordemos também que o leitor não enfrenta o texto como tábula rasa: a mente do leitor é muito mais tábula plena, cheia de preconceitos. Os preconceitos do leitor não devem amordaçar o texto, não devem silenciá-lo. Como disse Hans-Georg Gadamer (1900-2002), filósofo alemão fundador da hermenêutica contemporânea: "quem quiser compreender um texto deve estar pronto a deixar que ele lhe diga alguma coisa" (REALE; ANTISERI, 2007, p. 631). Lembremos que tábula era uma tábua encerada usada na Roma Antiga para escrever. Tábula é sinônimo de códice, pugilar e tabuinha.
} 
freiriano é dialético e não admite sequências rígidas e inflexíveis ou leis metodológicas absolutas ${ }^{16}$. Talvez pareça contraditório relacionar Paulo Freire e aula expositiva, afinal a técnica expositiva é criticada por Freire (2010) nestes termos: na concepção "bancária" da educação, educar é o ato de depositar, de transferir, de transmitir valores e conhecimentos. A narração transforma os educandos em "vasilhas" a serem enchidas pelo educador. De maneira que, na visão "bancária" da educação:

a) o educador é o que educa; os educandos, os que são educados; b) o educador é o que sabe; os educandos, os que não sabem; c) o educador é o que pensa; os educandos, os pensados; d) o educador é o que diz a palavra; os educandos, os que a escutam docilmente; e) o educador é o que disciplina; os educandos, os disciplinados; f) o educador é o que opta e prescreve sua opção; os educandos, os que seguem a prescrição: g) o educador é o que atua; os educandos, os que têm a ilusão de que atuam, na atuação do educador; h) o educador escolhe o conteúdo programático; os educandos, jamais ouvidos nesta escolha, se acomodam a ele; i) o educador identifica a autoridade do saber com sua autoridade funcional, que opõe antagonicamente à liberdade dos educandos; estes devem adaptarse às determinações daquele; j) o educador, finalmente, é o sujeito do processo: os educandos, meros objetos (FREIRE, 2010, p. 68).

Em oposição à educação "bancária", Freire (2010) defende uma concepção problematizadora da educação, na qual o diálogo é fundamental. É a ideia-chave que buscamos aproveitar: incluir o diálogo nas aulas. Há quem afirme que "o mais alto ensinamento do mestre não está no que ele diz, mas no que ele não diz” (GUSDORF, 1970, p. 147). Pode existir diálogo implícito entre o professor e os alunos: "O aluno intervém na aula, mesmo sem conversar; bastará olhar seu rosto para compreendê-lo; seus olhos

\footnotetext{
16 “'A rigor não se poderia falar em 'método' Paulo Freire pois se trata muito mais de uma teoria do conhecimento e de uma filosofia da educação do que de um método de ensino" (GADOTTI, 2004, p. 32, grifo do autor).
} 
dirão” (LOMBARDO-RADICE, 1950, p. 123, tradução nossa17). Neste trabalho, todavia, não discutiremos os estudos sobre comunicação nãoverbal. Passemos às sugestões para tornar a aula expositiva um facilitador da aprendizagem dos educandos.

Paulo Freire recomenda que respeitemos os saberes dos educandos:

Por isso mesmo pensar certo coloca ao professor ou, mais amplamente, à escola, o dever de não só respeitar os saberes com que os educandos, sobretudo os das classes populares, chegam a ela - saberes socialmente construídos na prática comunitária mas também, como há mais de trinta anos venho sugerindo, discutir com os alunos a razão de ser de alguns desses saberes em relação com o ensino dos conteúdos (FREIRE, 2007, p. 30).

Então, devemos começar nossas aulas sondando o conhecimento prévio dos alunos. Para isso, usaremos o diálogo. $\mathrm{O}$ ato inicial de cada aula será, portanto, descobrir o que o educando já sabe, o que realmente aprendeu nas aulas anteriores. Conduziremos o processo de ensino aprendizagem de acordo com o que o aluno já sabe. Devemos colocar em prática a ideia de aprender com nossos alunos. Não há docência sem discência: "O melhor mestre não é o que se impõe, o que se afirma como dominador do espaço mental, mas, muito pelo contrário, o que se torna aluno do seu aluno" (GUSDORF, 1970, p. 14).

Durante nossas aulas, e antes mesmo das aulas, podemos e devemos usar diversos questionamentos:

Freire insiste que questões como 'o quê', 'por quê?', 'como?', 'para que fim?', 'para quem?', são centrais em qualquer atividade educacional. Cada educador tem de formular essas questões e respondê-las; isso será um guia crucial para qualquer projeto educacional crítico (APPLE; GANDIN; HYPOLITO, 2011, p. 163).

\footnotetext{
17 Texto original (em espanhol): "El alumno interviene en la lección, aunque sin conversar; bastará mirarle a la cara para comprenderlo; sus ojos lo dirán” (LOMBARDO-RADICE, 1950, p. 123).
} 
A alegria é um fator muito importante em nossas aulas. Afinal "a atividade docente de que a discente não se separa é uma experiência alegre por natureza" (FREIRE, 2007, p. 142). Além disso,

É digna de nota a capacidade que tem a experiência pedagógica para despertar, estimular e desenvolver em nós o gosto de querer bem e o gosto da alegria sem a qual a prática educativa perde o sentido. É esta força misteriosa, às vezes chamada vocação, que explica a quase devoção com que a grande maioria do magistério nele permanece, apesar da imoralidade dos salários. E não apenas permanece, mas cumpre, como pode, seu dever. Amorosamente, acrescento (FREIRE, 2007, p. 142).

A educação é uma tarefa tão bela que não pode desenvolver-se em meio à tristeza: "É concebível um pintor ou escultor que trabalhe cheio de angústia, de ódio ou de rebelião contra as figuras de sua arte? E aqui [na educação] se trata de pintar e de compor almas [...]” (HUBERT, 1968, p. 553, tradução nossa ${ }^{18}$ )

Entre os educadores, é consenso que devemos dominar o conteúdo dos cursos que vamos ministrar. Quanto mais soubermos do conteúdo, melhor será, pois, ao invés de nos preocuparmos com o conteúdo na aula, poderemos prestar mais atenção aos alunos. O professor precisa, portanto, se qualificar permanentemente: "O professor que não leve a sério sua formação, que não estude, que não se esforce para estar à altura de sua tarefa não tem força moral para coordenar as atividades de sua classe” (FREIRE, 2007, p. 92).

Outra questão importante é aumentar a autonomia dos alunos. Existem, contudo, limites: “A liberdade sem limite é tão negada quanto a liberdade asfixiada ou castrada" (FREIRE, 2007, p. 105).

\footnotetext{
${ }^{18}$ Texto original (em espanhol): “ ¿Se concibe a un pintor o a un escultor que trabajen poseídos de angustia, de odio o de rebelión contra las figuras de su arte? Y aquí se trata de pintar y de escribir almas [...]" (HUBERT, 1968, p. 553).
} 
O educador deve ter ética: "Não é possível pensar os seres humanos longe, sequer, da ética, quanto mais fora dela. Estar longe, ou pior, fora da ética, entre nós, mulheres e homens, é uma transgressão" (FREIRE, 2007, p. $33)$.

No mundo contemporâneo é muito importante conviver com pessoas diferentes:

O meu respeito de professor à pessoa do educando, à sua curiosidade, à sua timidez, que não devo agravar com procedimentos inibidores exige de mim o cultivo da humildade e da tolerância. Como posso respeitar a curiosidade do educando se, carente de humildade e da real compreensão do papel da ignorância na busca do saber, temo revelar o meu desconhecimento? Como ser educador, sobretudo numa perspectiva progressista, sem aprender, com maior ou menor esforço, a conviver com os diferentes? Como ser educador, se não desenvolvo em mim a indispensável amorosidade aos educandos com quem me comprometo e ao próprio processo formador de que sou parte? Não posso desgostar do que faço sob pena de não fazê-lo bem (FREIRE, 2007, p. 67).

O professor deve buscar a unidade na diversidade: "A unidade na diversidade pressupõe o não sectarismo, a tolerância segundo a qual a virtude revolucionária consiste na convivência com os diferentes para melhor enfrentar os antagônicos" (ZANETTI, 2010, p. 191, grifo do autor).

A aprendizagem é facilitada quando o professor quer bem ao educando:

E o que dizer, mas sobretudo que esperar de mim, se, como professor, não me acho tomado por este outro saber, o de que preciso estar aberto ao gosto de querer bem, às vezes, à coragem de querer bem aos educandos e à própria prática educativa de que participo (FREIRE, 2007, p. 141). 
Entre os principais objetivos do ensino-aprendizagem, temos o desejo de tornar críticos e autocríticos os nossos alunos:

Uma das tarefas essenciais da escola, como centro de produção sistemática de conhecimento, é trabalhar criticamente a inteligibilidade das coisas e dos fatos e a sua comunicabilidade. É imprescindível portanto que a escola instigue constantemente a curiosidade do educando em vez de "amaciá-la" ou "domesticá-la" (FREIRE, 2007, p. 123-124).

É necessário criar oportunidades para que os educandos cultivem a inteligência, para que pensem por si mesmos ${ }^{19}$.

Se fosse necessário escolher o mais importante princípio na vida e na obra do Paulo Freire, certamente tal princípio seria o uso do diálogo. Outros autores também afirmam a importância de usar a palavra. Por exemplo, Édouard Claparède (1873-1940), neurologista, psicólogo e educador suíço, observa com justeza que "a palavra é, para quem fala, invenção e, para quem ouve, compreensão" (CLAPARÈDE, 1958b, p. 112). Devemos ressaltar que o diálogo freiriano busca conscientizar o oprimido. É um diálogo multilateral, ou seja, diálogo entre professor e alunos e entre os alunos. Diálogo sincero: "Somente quem escuta paciente e criticamente o outro, fala com ele, mesmo que em certas condições, precise de falar a ele” (FREIRE, 2007, p. 113, grifo do autor).

Podemos e precisamos usar palavras, mas devemos agir de acordo com o que falamos! "A libertação autêntica, que é a humanização em processo, não é uma coisa que se deposita nos homens. Não é uma palavra a

\footnotetext{
19 "Cultivar a inteligência é dar ao indivíduo oportunidade de pesquisar. Assim como é na forja que se formam os ferreiros, assim também é na pesquisa que se cultiva a inteligência” (CLAPARÈDE, 1958d, p. 182). A escola tradicional, contudo, fortalece em nós tendências que deveríamos combater: "Com efeito, sugar docemente o pensamento alheio é bem menos fatigante que mobilizar nosso pensamento! Ler, refestelado em cômoda poltrona é bem mais agradável que mexer-se para pesquisar! E, finalmente, aceitar opiniões já formadas é bem mais cômodo que formular opinião pessoal, com conhecimento de causa!" (CLAPARĖDE, 1958d, p. 184). No fundo, ainda buscamos realizar o lema do iluminismo: Sapere aude! (Ouse pensar!), ou seja, queremos que os educandos tenham a coragem de servir-se de sua própria inteligência.
} 
mais, oca, mitificante. É práxisis ${ }^{20}$, que implica a ação e a reflexão dos homens sobre o mundo para transformá-lo" (FREIRE, 2010, p. 77, grifo do autor). Ensinar exige a corporeificação das palavras pelo exemplo:

O professor que realmente ensina, quer dizer, que trabalha os conteúdos no quadro da rigorosidade do pensar certo, nega, como falsa, a fórmula farisaica do "faça o que mando e não o que eu faço". Quem pensa certo está cansado de saber que as palavras a que falta a corporeidade do exemplo pouco ou quase nada valem. Pensar certo é fazer certo (FREIRE, 2007, p. 34).

Em essência, apresentamos neste trabalho, com base nos princípios educacionais freirianos, dez sugestões para que as potencialidades da aula expositiva sejam aproveitadas ao máximo. Ei-las: usar o diálogo, ter ética, respeitar os saberes prévios dos alunos, domínio do conteúdo, respeitar o diferente, conceder autonomia aos alunos, tornar críticos os alunos, querer bem aos educandos, ter alegria e ser coerente.

É interessante notar que fizemos um levantamento entre os alunos de pós-graduação (mestrado e doutorado) em ciências exatas, da Universidade Federal de Goiás - Regional Catalão, com o objetivo de determinar as qualidades consideradas pelos mesmos como as mais eficientes para a docência (ANDREATA; BARROS, 2017b). Com o mesmo propósito, fizemos também um levantamento entre os alunos da graduação em Física (ANDREATA; SOUZA, 2013). Utilizamos a técnica do questionário autoaplicado com questões abertas sobre o professor e sua prática. Nossos levantamentos indicam que, em geral, os graduandos e os pós-graduandos em ciências exatas acreditam, em desacordo com Paulo Freire, que pode haver docência sem discência, que ensinar é transferir conhecimentos e, além disso, não mencionam os aspectos humanos e políticos da educação. É

\footnotetext{
${ }^{20}$ Práxis: ação e, sobretudo, ação ordenada para um certo fim (por oposição a conhecimento, a teoria).
} 
muito importante, portanto, estimular os professores, em especial os iniciantes, a aproveitar as sugestões mencionadas neste trabalho.

\section{Conclusão}

Discutimos as principais vantagens e desvantagens da aula expositiva, apresentamos as características de uma boa aula expositiva e, com base nos princípios educacionais freirianos, fizemos dez sugestões para que as potencialidades da aula expositiva sejam aproveitadas ao máximo. Em especial, destacamos a importância de incluir nas aulas o diálogo entre professor e educandos e entre os educandos. O diálogo não é apenas um meio educativo, mas o recurso pelo qual se produz a própria educação.

Recordemos que "o educador não é um robô, um simples servente da pedagogia. Deve conhecer as razões da utilização deste ou daquele método pedagógico, os fatores utilizados na aplicação de uma técnica e ser capaz de assegurar e avaliar a coerência da sua ação educativa" (MIALARET, 1981, p. 21). Além disso, "a experiência nos convenceu de que não há métodos bons nem maus; isto é, métodos aos quais devamos sujeitar-nos. O melhor é não ter nenhum exclusivo e conhecer todos para empregá-los com discernimento adequado" (TOLSTÓI apud LARROYO, 1970, p. 757).

Nossa proposta é aplicável em qualquer sala de aula, tanto urbana quanto rural, sem a necessidade de dispor de recursos sofisticados.

\section{Referências}

AGUAYO, Alfredo Miguel. Didática da escola nova. Tradução de João Baptista Damasco Penna e Antônio d'Ávila. 14. ed. São Paulo: Nacional, 1970. 368 p. [Título original (em espanhol): Didáctica de la escuela nueva, 1932.]

ANASTASIOU, Léa das Graças Camargos. Ensinar, aprender, apreender e processos de ensinagem. In: .; ALVES, L. P. (orgs.). Processos de ensinagem na universidade: pressupostos para as estratégias de trabalho em aula. 8. ed. Joinville: Univille, 2009. 155 p. 
ANDREATA, Mauro Antonio; BARROS, Fernanda. Centros de interesse nas aulas de física do ensino superior. In: FALEIRO, Wender; ASSIS, Maria Paulina de (orgs.). Ciências da natureza e formação de professores: entre desafios e perspectivas apresentados no CECIFOP 2017. Jundiaí/SP: Paco, 2017a. 384 p. Disponível em: $<$ http://docs.wixstatic.com/ugd/898a9f_b09cebdda4614e148a31318d9792fcac.pdf> . Acesso em: 18 fev. 2018.

. O bom professor segundo os alunos de pós-graduação em ciências exatas. In: CONGRESSO NACIONAL DE ENSINO DE CIÊNCIAS E FORMAÇÂO DE PROFESSORES, 1., 2017b, Catalão. Disponível em : $<$ http://cecifop.sistemasph.com.br/index. php/cecifop /CECIFOP2017>. Acesso em: 18 fev. 2018.

ANDREATA, Mauro Antonio; SOUZA, Thaianne Lopes de. O bom professor segundo os alunos universitários de física. Itinerarius Reflectionis, Jataí, v. 2, n. 15, p. 1-10, 2013. Disponível em: <https://www.revistas.ufg.br/rir/article/view/27514/19275>. Acesso em: 18 fev. 2018 .

APPLE, Michael W.; GANDIN, Luís Armando; HYPOLITO, Álvaro Moreira. Paulo Freire 1921 - 97. In: PALMER, Joy A. (org.). 50 grandes educadores modernos: de Piaget a Paulo Freire. Tradução de Mirna Pinsky. 2. ed. São Paulo: Contexto, 2011. 351 p. [Título original (em inglês): Fifty modern thinkers on education: from Piaget to the present, 2006.]

BARTOLOMEIS, Francesco de. Introdução à didáctica da escola activa. Tradução de José Luís Borges Coelho. Lisboa: Livros Horizonte, 1984. 323 p. [Título original (em italiano): Introduzione alla didattica della scuola attiva, 1953.]

BHATTACHARYA, Asoke. Paulo Freire: Rousseau of the twentieth century. Rotterdam: Sense Publishers, 2011. 311 p.

BORDENAVE, Juan Díaz; PEREIRA, Adair Martins. Estratégias de ensinoaprendizagem. 29. ed. Petrópolis: Vozes, 2008. 316 p.

CLAPARÈDE, Édouard. Introdução: psicologia, biologia, educação. In: . $A$ educação funcional. Tradução de João Baptista Damasco Penna. 5. ed. São Paulo: Nacional, 1958a. 294 p. [Título original (em francês): L'éducation fonctionnelle, 1931.]

A psicologia da inteligência. In: A educação funcional. Tradução de João Baptista Damasco Penna. 5. ed. São Paulo: Nacional, 1958b. 294 p. [Título original (em francês): L'éducation fonctionnelle, 1931.]

A psicologia da escola ativa. In: A educação funcional. Tradução de João Baptista Damasco Penna. 5. ed. São Paulo: Nacional, 1958c. 294 p. [Título original (em francês): L'éducation fonctionnelle, 1931.] 
Reflexões de um psicólogo. In: . A educação funcional. Tradução de João Baptista Damasco Penna. 5. ed. São Paulo: Nacional, 1958d. 294 p. [Título original (em francês): L'éducation fonctionnelle, 1931.]

CLAUSSE, Arnould. A relatividade educativa: esboço de uma história e de uma filosofia da escola. Coimbra: Almedina, 1976. 331 p. [Título original (em francês): La relativité educationnelle, 1975.]

COSTA, Cruz. Platão. In: ; BELLO, Ruy de Ayres; D’AVILA, Antônio; PENNA, João Baptista Damasco. Grandes educadores. Porto Alegre: Globo, 1949. $333 \mathrm{p}$.

FREIRE, Paulo. Pedagogia da autonomia: saberes necessários à prática educativa. 35. ed. São Paulo: Paz e Terra, 2007. 146 p. [A primeira edição é de 1996.]

. Pedagogia do oprimido. São Paulo: Paz e Terra, 2010. 213 p. [A primeira edição, publicada em inglês, é de 1970.]

FROTA-PESSOA, Oswaldo; GEVERTZ, Rachel; DA SILVA, Ayrton Gonçalves. Como ensinar ciências. São Paulo: Nacional/EDUSP, 1970. 218 p.

GADOTTI, Moacir. Convite à leitura de Paulo Freire. 2. ed. 4. reimp. São Paulo: Scipione, 2004. 175 p.

GAL, Roger. História da educação. Tradução de Álvaro Cabral. São Paulo: Martins Fontes, 1989. 115p. [Título original (em francês): Histoire de l'éducation, 1948.]

GAUTHIER, Clermont; TARDIF, Maurice (orgs.). A pedagogia: teorias e práticas da Antiguidade aos nossos dias. Tradução de Guilherme João de Freitas Teixeira. 2. ed. rev. e atual. Petrópolis: Vozes, 2013. 477 p. [Título original (em francês): La pédagogie: théories et pratiques de l'Antiquité à nos jours, 3. ed., 2012.]

GHIRALDELLI Jr., Paulo. História da educação. 2. ed. São Paulo: Cortez, 1994. $240 \mathrm{p}$.

GUSDORF, Georges. Professores para quê?: para uma Pedagogia da Pedagogia. Tradução de João Bénard da Costa e António Ramos Rosa. 2. ed. Lisboa: Moraes, 1970. 319 p. [Título original (em francês): Pourquoi des professeurs?, 1963.]

HEUVELEN, Alan Van. Learning to think like a physicist: a review of researchbased instructional strategies. American Journal of Physics, Melville, v. 59, n. 10, p. 891-897, out. 1991.

HUBERT, René. Tratado de pedagogía general. Tradução em espanhol de Juana Castro. 5. ed. 1. reimp. Buenos Aires: El Ateneo, 1968. 602 p. [Título original (em francês): Traité de pédagogie genéral, 1946.]

LARROYO, Francisco. História geral da pedagogia. Tradução de Luiz Aparecido Caruso. São Paulo: Mestre Jou, 1970. v. 2. 499 p. [Título original (em espanhol): Historia general de la pedagogía, 10. ed., 1967.] 
LEIF, Joseph Jacques; RUSTIN, Georges. Pedagogia geral: pelo estudo das doutrinas pedagógicas. Tradução de Luiz Damasco Penna e João Baptista Damasco Penna. São Paulo: Nacional, 1960. 429 p. [Título original (em francês): Pédagogie générale par l'étude des doctrines pédagogiques, 1953.]

LIMA, Lauro de Oliveira. Escola secundária moderna: organização, métodos e processos. 10. ed. Petrópolis: Vozes, 1973. 670 p.

$63 \mathrm{p}$.

Mutações em educação segundo McLuhan. 12. ed. Petrópolis: Vozes, 1979.

LOMBARDO-RADICE, Giuseppe. Leccíones de didáctica y recuerdos de experiencia docente. Tradução em espanhol de Pablo Martínez de Salinas. 1. reimp. Barcelona: Labor, 1950. 483 p. [Título original (em italiano): Lezioni di didattica e ricordi di esperienza magistrale, 1912.]

MARTINS FILHO, Eduardo Lopes. Manual de redação e estilo de O Estado de São Paulo. 3. ed. rev. ampl. São Paulo: O Estado de São Paulo, 1997. 400 p.

MATTOS, Luiz Alves de. Sumário de didática geral. 2. ed. Rio de Janeiro: Aurora, 1959. $463 \mathrm{p}$.

MAYER, Frederick. História do pensamento educacional. Tradução de Helena Maria Camacho. Rio de Janeiro: Zahar, 1976. 666 p. [Título original (em inglês): A history of educational thought, 3. ed., 1973.]

MEZIROW, Jack. Visão geral sobre a aprendizagem transformadora. In: ILLERIS, Knud (org.). Teorias contemporâneas da aprendizagem. Tradução de Ronaldo Cataldo Costa. Porto Alegre: Penso, 2013. 280 p. [Título original (em inglês): Contemporary theories of learning: learning theorists... in their own words, 2009.]

MIALARET, Gaston. A formação dos professores. Tradução de Joaquim Filipe Machado. Coimbra: Almedina, 1981. 163 p. [Título original (em francês): La formation des enseignants, 1977.]

MOREIRA, Marco Antonio. Atividade docente na universidade: alternativas instrucionais. Porto Alegre: Luzzatto Editores/Rio Grande: Editora da FURG, 1985. $136 \mathrm{p}$.

Teorias de aprendizagem. 2. ed. ampl. reimp. São Paulo: EPU, 2015. 248 p.

NÉRICI, Imídeo Giuseppe. Introdução à didática geral: dinâmica da escola. 7. ed. Rio de Janeiro: Fundo de Cultura, 1968. 512 p.

PILETTI, Claudino. Didática geral. 8. ed. São Paulo: Ática, 1987. 258 p.

RAYMONT, Thomas. Educação moderna: objetivos e métodos. Tradução de Manuel Campos. 2. ed. Rio de Janeiro: Fundo de Cultura, 1961. 266 p. [Título original (em inglês): Modern Education: its aims and methods, 4. ed, 1953.] 
REALE, Giovanni; ANTISERI, Dario. História da filosofia. [Tradução de Ivo Storniolo.] 8. ed. São Paulo: Paulus, 2007. v. 3. 1141 p. [Título original (em italiano): Il pensiero occidentale dalle origini ad oggi, 1986.]

ROUSSEAU, Jean-Jacques. Emílio ou da educação. Tradução de Roberto Leal Ferreira. 3. ed. São Paulo: Martins Fontes, 2004. 711 p. [Título original (em francês): Émile ou de l'éducation, 1762.]

THORNDIKE, Edward Lee; GATES, Arthur I. Princípios elementares de educação. Tradução de Haydée Bueno de Camargo. São Paulo: Saraiva, 1936. 396 p. [Título original (em inglês): Elementary principles of education, 1929.]

VASCONCELLOS, Celso dos Santos. Construção do conhecimento em sala de aula. 19. ed. São Paulo: Libertad, 2014. 144 p.

ZANETTI, Maria Aparecida. Pedagogia da esperança: reflexões sobre o reencontro com a pedagogia do oprimido. In: SOUZA, Ana Inês (org.). Paulo Freire: vida e obra. 2. ed. São Paulo: Expressão Popular, 2010. 343 p. 